\title{
PERCEPÇÃO AMBIENTAL DOS ALUNOS DO CURSO DE GESTÃO AMBIENTAL
}

Magaly de Souza Alves ${ }^{1}$, José Cavalcante Lacerda Junior ${ }^{2}$, Mônica Alves de Vasconcelos ${ }^{3}$, Maria Inês Gaspareto Higuchi ${ }^{4}$, Henrique dos Santos Pereira ${ }^{5}$

\section{RESUMO}

O artigo objetiva diagnosticar a percepção ambiental dos alunos de um Curso de Gestão Ambiental em Manaus, Amazonas. Nesse trabalho foi utilizado um questionário préestabelecido formulado com perguntas fechadas e abertas, com amostra de 34 alunos. Os dados foram analisados por meio do diálogo entre autores da Percepção Ambiental. Como resultado, elaborou-se um cenário para compreensão das interrelações dos sujeitos com o ambiente. Conhecendo a realidade desta comunidade, projetos de educação ambiental poderão ser realizados para atender às necessidades encontradas nesta população. Como resultado, observase o envolvimento ambiental dos alunos apesar da necessidade de criação e realização de projetos de educação ambiental.

PALAVRAS-CHAVE: percepção ambiental; universidade; educação ambiental.

\section{ABSTRACT}

The article aims to diagnose the environmental perception of the students of an Environmental Management Course in Manaus, Amazonas. In this study, a pre-established questionnaire was formulated with closed and open questions, with a sample of 34 students. The data were analyzed through the dialogue between authors of Environmental Perception. As a result, a scenario was elaborated to understand the subjects' interrelationships with the environment. Knowing the reality of this community, environmental education projects can be carried out to meet the needs found in this population. As a result, it was observed the environmental involvement of students despite the need of creating and carrying out environmental education projects.

KEYWORDS: environmental perception; university; environmental education.

\section{INTRODUÇÃO}

A complexidade de nosso tempo (MORIN, 2007) tenciona sua discussão sobre a relação do ser humano com o ambiente, a qual traz em seus meandros a interdisciplinaridade como tessitura dessa conjuntura. Tal compreensão "toca" a percepção que se constrói do ambiente, onde reflexões e práticas podem compartilhar

\footnotetext{
1 Faculdade Salesiana Dom Bosco

2 Universidade Federal do Amazonas.

3 Universidade Federal do Amazonas.

4 Universidade Federal do Amazonas.

5 Universidade Federal do Amazonas.
} 
ISSN- 1413-8638

E-ISSN - 2238-5533

v. 22 , n. 1, p. $333-348,2017$

significados e sentidos que transcendam seu escopo epistemológico, revelando o processo de entendimento mundo. Desde que o ser humano surgiu na Terra vem alterando o ambiente (DIAS, 2004). Com a Revolução Industrial essas alterações se tornaram mais evidentes e potencialmente mais devastadoras. Dessa maneira, novos rumos dessa relação foram estabelecidos e o exercício do cuidado deve atuar de maneira significativa tonar-se necessário. Para tanto, no campo da Educação Ambiental - EA uma maneira que vem contribuindo para esse percurso é a percepção ambiental uma vez que se conhece e re-conhece os "olhares" dos sujeitos, incluindo os elementos da natureza e outros organismos (MARQUES et al, 2010).

Concebe-se, ainda, a percepção ambiental não restrita aos elementos físico e biológico do ambiente, mas como processo que engloba o aspecto sociocultural e suas relações com os modelos de desenvolvimento adotados pelo ser humano. Dessa maneira, tudo o que é visto, sentido e ouvido, está acoplado na maneira pela qual este meio é percebido, “[...] a percepção é justamente uma interpretação com o fim de nos restituir a realidade objetiva, através da atribuição de significado aos objetos percebidos [...]" (OLIVEIRA, 1997, p. 62).

Nesse sentido, os trabalhos voltados para a conservação do meio ambiente necessitam compreender como os envolvidos no processo percebem, reagem e respondem sobre as ações que os envolvem. Implica, também, em compreender a percepção como algo individual, onde cada ser se apresenta de maneira diferente perante estas questões. Conhecer o seu lugar no meio torna-se importante no desenvolvimento de ações que beneficiem a todos, buscando consolidação de atitudes positivas em relação ao meio ambiente. Logo, desenvolver pesquisas que busquem a percepção dos envolvidos, dos seus conhecimentos sobre o ambiente, de como eles o veem e lidam com as questões são importantes elementos no levantamento de subsídios que auxiliem na elaboração de propostas para a melhoria dessas interações.

Dessa maneira, o presente artigo objetiva apresentar a percepção ambiental dos alunos de um curso de gestão ambiental na Cidade de Manaus. Como estratégia metodológica, recorreu-se a uma pesquisa documental, onde foram levantados dados de publicações para embasar a pesquisa. Aplicou-se, ainda, uma entrevista por meio de um questionário semiestruturado compostos por perguntas fechadas e abertas, de modo a 
conhecer o perfil dos alunos do curso, além de buscar conhecer a sua percepção ambiental.

Assim, o referido texto está organizado em dois tópicos, a saber: 1) Caracterizando o local e os sujeitos da pesquisa; 2) Percepção Ambiental dos alunos. Por fim, acredita-se que os dados advindos do presente estudo possibilita uma reflexão acerca da percepção ambiental na cidade de Manaus, oportunizando reconhecer elementos que colaboram no entendimento da relação do ser humano com o ambiente.

\section{CARACTERIZANDO O LOCAL E OS SUJEITOS DA PESQUISA}

A pesquisa ocorreu na Faculdade Salesiana Dom Bosco - FSDB por meio do Curso de Gestão Ambiental. A referida faculdade foi fundada em 2000 e está credenciada pela portaria 1.166/ 2002/MEC. Filiada a Inspetoria Salesiana Missionária da Amazônia, que atua na área educacional desde 1921 em Manaus, a FSDB possui duas unidades: Unidade Centro e Unidade Leste, lócus da pesquisa.

Com efeito, o objetivo do Curso de Gestão Ambiental é formar profissionais com competências necessárias para atuarem de forma efetiva no gerenciamento ambiental, estudando e desenvolvendo ações e práticas aplicáveis a um mercado com características fortemente competitivas, nem sempre compromissadas com a preservação e sustentabilidade ambiental.

Historicamente, a faculdade assim como a escola desempenha papel importante no desenvolvimento de atividades de EA, onde circulam informações, conhecimentos são construídos e propostas de intervenções pedagógicas e políticas auxiliam na formação de cidadãos mais críticos perante as questões ambientais e as demais problemáticas do ser no mundo (CASTOLDI et al 2009).

Dessa maneira, para desenvolver atividades de EA, em qualquer nível de ensino, torna-se necessário, inicialmente, conhecer a percepção ambiental do estudando no meio ao que convive. Logo, estudos de percepção são importantes porque cada um tem uma visão própria do mundo ao seu redor. O reconhecimento das percepções individuais no que diz respeito ao ambiente possibilita a leitura do mundo e suas interfaces ideológicas de maneira mais realista, gerando segurança e podendo desvendar o mundo e criar condições para melhorá-lo a partir dos próprios sujeitos (RUCHEINSKY, 2001). 
No que diz respeito aos participantes da pesquisa, através da aplicação do questionário, alcançou 34 alunos do curso de Gestão Ambiental, isto é, do primeiro ao quarto período do supracitado curso. O procedimento para a tabulação de dados foi a de planilhas no Excel. Após tabulação os dados foram convertidos em tabelas e gráficos para uma melhor compreensão e análise dos resultados obtidos.

Dos alunos que responderam o questionário, a maioria representando $60 \%$, é natural de Manaus, tendo ainda alunos de Manacapuru, Lábrea, Codajás e São Paulo de Olivença, ambos do estado do Amazonas. Os demais são de Santarém, Juruti e Itaituba no Pará e um aluno de Boa Vista, Roraima.

Nos três primeiros períodos do curso, a maioria dos questionários foi respondida por alunos do sexo feminino, sendo três do primeiro, nove e oito, do segundo e terceiro periodo, respectivamente. Apenas o último periodo apresentou uma maior representatividade masculina, com sete alunos. Como pode ser observado no Gráfico 1 , dos alunos entrevistados, $18 \%$ apenas tem idade menor que 20 anos. Sendo as maiores representatividas de alunos com idade entre 21 e 40 anos com 59\%. E ainda, 21\% alunos com mais de 40 anos de idade, o que demonstra uma diversidade etária entre os alunos do curso.

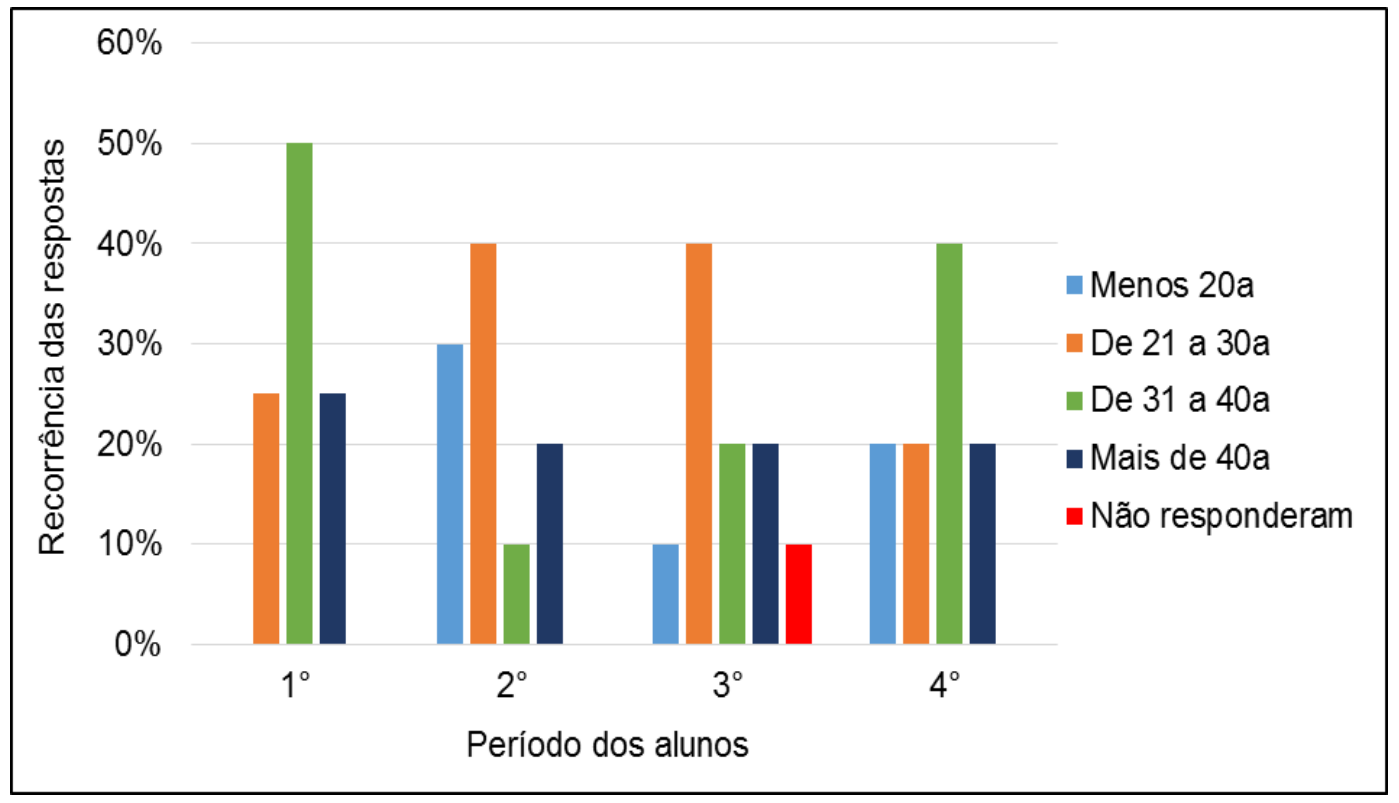

Gráfico 1: Faixa etária dos alunos

O reconhecimento das percepcões dos sujeitos incita a autonomia e o respeito pelo aspecto ontológico daquele que possui uma visão de mundo e daquilo que está em 
seu entorno. Evidencia-se que a ressonância de um grupo social é tanto maior quanto menor for a distância (social) que o indivíduo mantêm, isto é, a participação dos sujeitos não somente lhes concede autonomia, mas torna-se mais efetiva na medida em que se sentem membros próximos as atividades (BOURDIEU, 1996).

Portanto, essa perspectiva instala uma compreensão que leva em consideração o aspecto ontológico dos participantes, isto é, uma visão e uma perspectiva acerca do seu mundo e daquilo que está em seu entorno. Assim, instaura-se o campo de interlocução com os participantes mediante suas percepções e produções (BRANDÃO, 1984). Desse modo, o que se pesquisou, fez-se com, isto é, conjuntamente sinalizando um diálogo mais próximo com a realidade. É essa perspectiva que atravessa o próximo tópico.

\section{A PERCEPÇÃO AMBIENTAL DOS ALUNOS}

O ritmo acelerado das informações, a fluidez do conhecimento e a sobreposição de antigos paradigmas convocam um repensar das práticas científicas-ambientais e, acima de tudo, um questionamento sobre a origem dos conceitos que circulam em nosso dia-a-dia. Por conseguinte, estabelece a necessidade constante de rever e atualizar os conceitos que auxiliam na percepção acerca do mundo marcado pelas constantes modificações do saber globalizado. Mais ainda, torna-se fundamental identificar a origem das informações, pois, uma das características do contexto contemporâneo é o papel despótico da informação manipulada que atende aos interesses específicos de grupos políticos (SANTOS, 2004).

[...] As novas condições técnicas deveriam permitir a ampliação do conhecimento do planeta, dos objetos que o forma, das sociedades que o habitam e dos homens em sua realidade intrínseca. Todavia, nas condições atuais, as técnicas de informação são principalmente utilizadas por um punhado de atores em função de seus objetivos particulares. [...] O que é transmitido à maioria da humanidade é, de fato, uma informação manipulada que, em lugar de esclarecer, confunde. (SANTOS, 2004, p.38-39)

Imerso nessa conjuntura, as fontes de origem do conhecimento sobre o ambiente são inúmeras. Dessa forma, os alunos foram questionados sobre as suas principais fontes de informações a respeito das questões ambientais. Do total, $41 \%$ disse que a internet é sua maior fonte de informação; $37 \%$ atribuiu a FSDB como sua maior fonte de informação por meio das aulas e eventos realizados na mesma; $18 \%$ disse se 
informar por meio da televisão, rádio e jornais; e apenas um aluno respondeu que se mantém informado por meio de amigos, como pode ser observado no Gráfico 2.

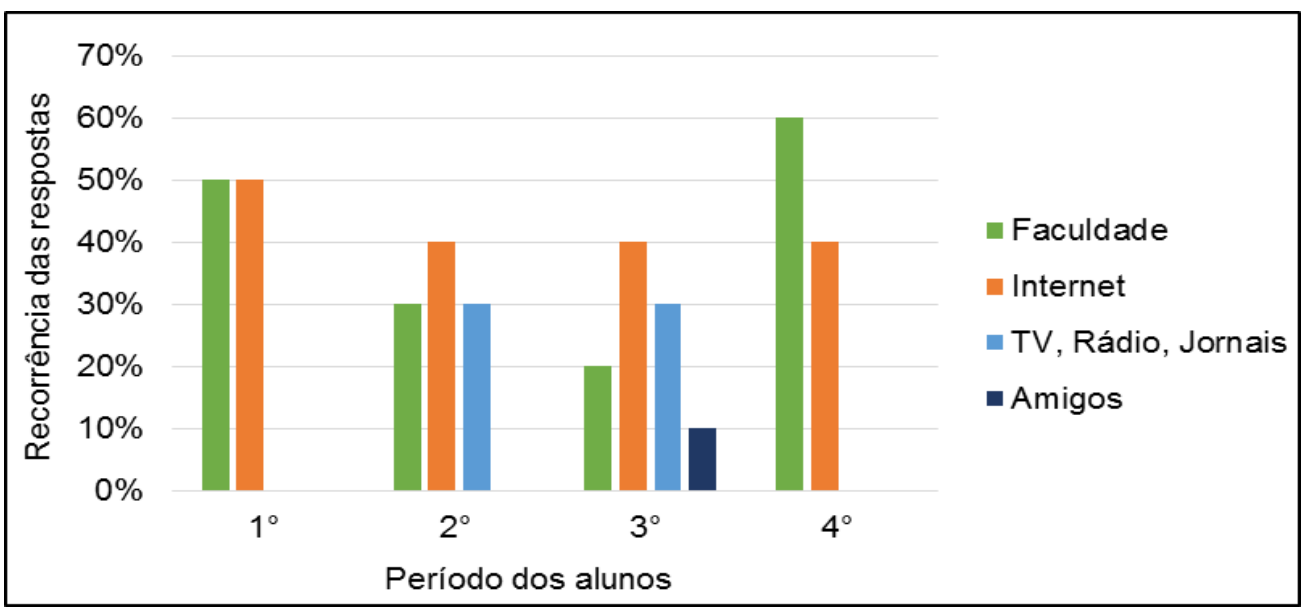

Gráfico 2: Fontes de informações ambientais

Observa-se, aqui, a influência da internet no contexto contemporâneo é inevitável. O avanço tecnológico e seu contínuo acesso aos meios educacionais acionam a internet como uma ferramenta essencial de aprendizagem. Contudo, deve se ressaltar o caráter efêmero das informações que o campo virtual carrega consigo. As mudanças constantes de publicações baseadas na livre opinião exigem do seu receptor a averiguação da veracidade das informações vinculadas (CABRAL et al, 2009)

Nesse intuito, torna-se mister, entender se os entrevistados possuíam ou não alguma formulação conceitual sobre o tema, isto é, meio ambiente. De acordo com o questionário, $100 \%$ respondeu sim. No entanto, ao serem solicitados para definir ambiente, de maneira resumida, nem todos o fizeram como observa-se no Gráfico 3.

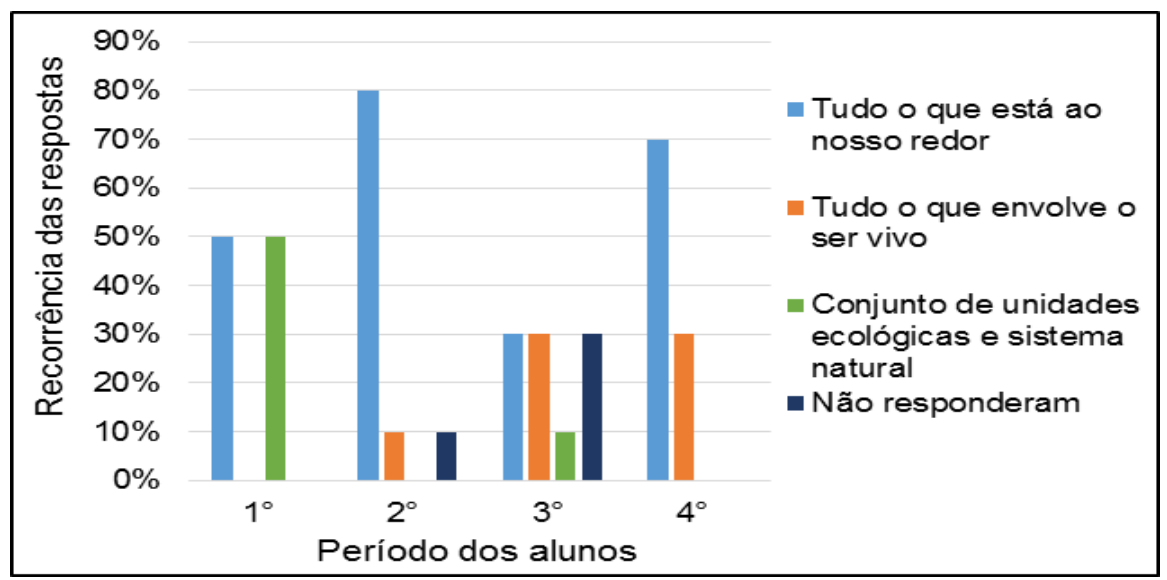

Gráfico 3: Definição de Meio Ambiente 
Dos 34 alunos, 59\% responderam que o meio ambiente é tudo o que está ao nosso redor; $20 \%$ definiu o meio ambiente como tudo o que envolve o ser vivo; seguido por $9 \%$ que descreveram o meio ambiente como conjunto de unidades ecológicas e sistema natural.

Essa percepção evidencia como o decurso da modernidade acabou por produzir uma concepção mecânica e fragmentada, visualizada na concepção cartesiana de ser humano e meio ambiente. Destaca-se que a ideia de conceber o meio ambiente como restrito aos fenômenos naturais está vinculada ao surgimento das ciências modernas (KINDEL, 2012). A visão mecanicista que nutriu as concepções filosóficas da modernidade proporcionou uma compreensão do ser humano e do meio ambiente a partir da fragmentação, isto é, a análise dualista cartesiana sobrepôs o ser humano (sujeito racional) ao meio ambiente (objeto passivo).

O contexto da complexidade (MORIN, 2007) exige, contudo, uma reposição epistemológica na forma de conceber o ambiente. Historicamente, ligado aos fenômenos naturais, isto é, o olhar da interdisciplinaridade como tessitura de tal conjuntura deve religar o entendimento de ambiente articulado em práticas que compartilham significados e reflexões sobre os aspectos humanos, culturais e sociais na compreensão do mundo.

Essa percepção de ambiente apartada da condição humana é, ainda, reforçada quando se reconhece a definição de EA dos entrevistados, onde apenas um disse não saber definir a EA, no entanto, como na questão anterior, nem todos souberam discorrer sobre a questão, com sete alunos com questão em branco, Gráfico 4.

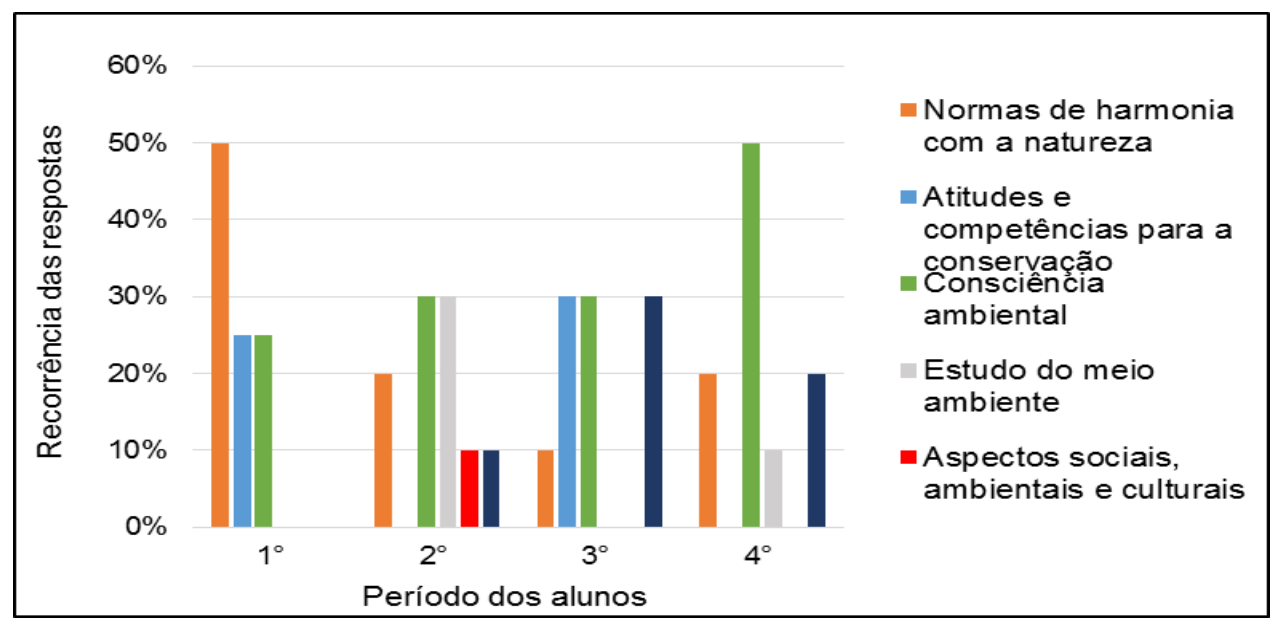


Segundo 35\% a EA é definida como a consciência ambiental da sociedade, a maior representatividade dessa definição ficou com o $4^{\circ}$ período do curso. Para sete alunos a EA é definida como normas de harmonia com a natureza; seguida por atitudes e competências para a conservação e estudo do meio ambiente com quatro alunos cada e apenas um aluno respondeu que a EA está realacionada aos aspectos sociais, ambientais e culturais da sociedade.

Conceber as questões ambientais apartadas das questões humanas exige o reconhecimento de uma Educação Ambiental que vislumbre a compressão da organicidade do meio, o que pode transmutar a perspectiva segregada ora percebida.

\begin{abstract}
Acredita-se em uma EA como uma nova filosofia de vida e que deve permear o nosso fazer científico e acadêmico. Não como uma educação apenas ecológica que busca, no conhecimento das relações entre seres vivos e seu ambienta natural, explicações parciais para fatos observáveis. Não como atividades esporádicas que coloquem as pessoas em contato com a natureza por um tempo limitado da vida. Não como disciplina a ser inserida nos currículos escolares e que pode se perder em mais um dos compartimentos de nossa prática cartesiana (LINDNER, 2012, p. 15).
\end{abstract}

A Educação Ambiental busca não só a conservação dos meios naturais, mas a valorização dos seres que neste meio vivem, desde valorizar sua importância social a respeitar sua cultura (MARQUES et al, 2010). Nessa mesma perspectiva, compreendese a EA como o processo por meio do quais o indivíduo e a coletividade constroem valores sociais, conhecimentos, habilidades, atitudes e competências voltadas para a conservação do meio ambiente (DIAS, 2004).

Observa-se que embora a compressão epistemólogica esteja atravessada pelos pressupostos fragmentados na modernidade, os entrevistados quandos foram abordados se eles causavam algum tipo de dano ao meio ambiente a maioria, cerca de $82 \%$, respondeu que sim, acredita que causa dano ao meio ambiente; $12 \%$ respondeu que não consideram que causam danos; um respondeu não saber e um não respondeu a essa questão.

Aqui reside, o entendimento de percepção ambiental enquanto tomada de consciência pelo homem (FAGIONATTO, 2007). A relevância dos estudos sobre percepção ambiental tornam-se uma decisiva fronteira no processo de reconsideração sobre a relação do ser humano com o ambiente, pois incide no reconhecimento da 
integralidade dos elementos. Além dessa perspectiva, oportuniza-se uma gestão mais eficiente e harmoniosa (AMORIM FILHO, 2007). A percepção atinge nossa sensorialidade e a transcende (OLIVEIRA, 1983).

[...] não é mera sensação dada pelos órgãos sensoriais. Vemos, ouvimos, sentimos, enfim, tudo aquilo que estimula nossos sentidos. Mas percebemos somente o que a nossa mente atribui significado. A percepção é altamente seletiva exploratória, antecipadora. Daí considerarmos uma atividade perceptiva, que nos explora, seleciona, compara, antecipa tudo o que percebemos [...]. (OLIVEIRA,1983, p. 48).

Dessa forma, quando questinados sobre se sentirem incomodados com algum aspecto relacionado ao meio ambiente, $79 \%$ deu resposta positiva, $12 \%$ respondeu que não e 9\% disse não saber o que sinaliza a incidência das problemáticas ambientais sobre o ser humano. Embora, a concepção de ambiente demonstre uma relação distante da condição humana, obseva-se que no aspecto da sensibilização há uma afetação que de alguma forma reforça o entendimento de que não é possível compreender ambiente e ser humano como unidades antagônicas, mas como um processo de uma integralidade aberta e dinâmica. Por isso, aos que responderam sim, foi solicitado dois exemplos desses aspectos de incômodo, como pode ser visualizado no Gráfico 5.

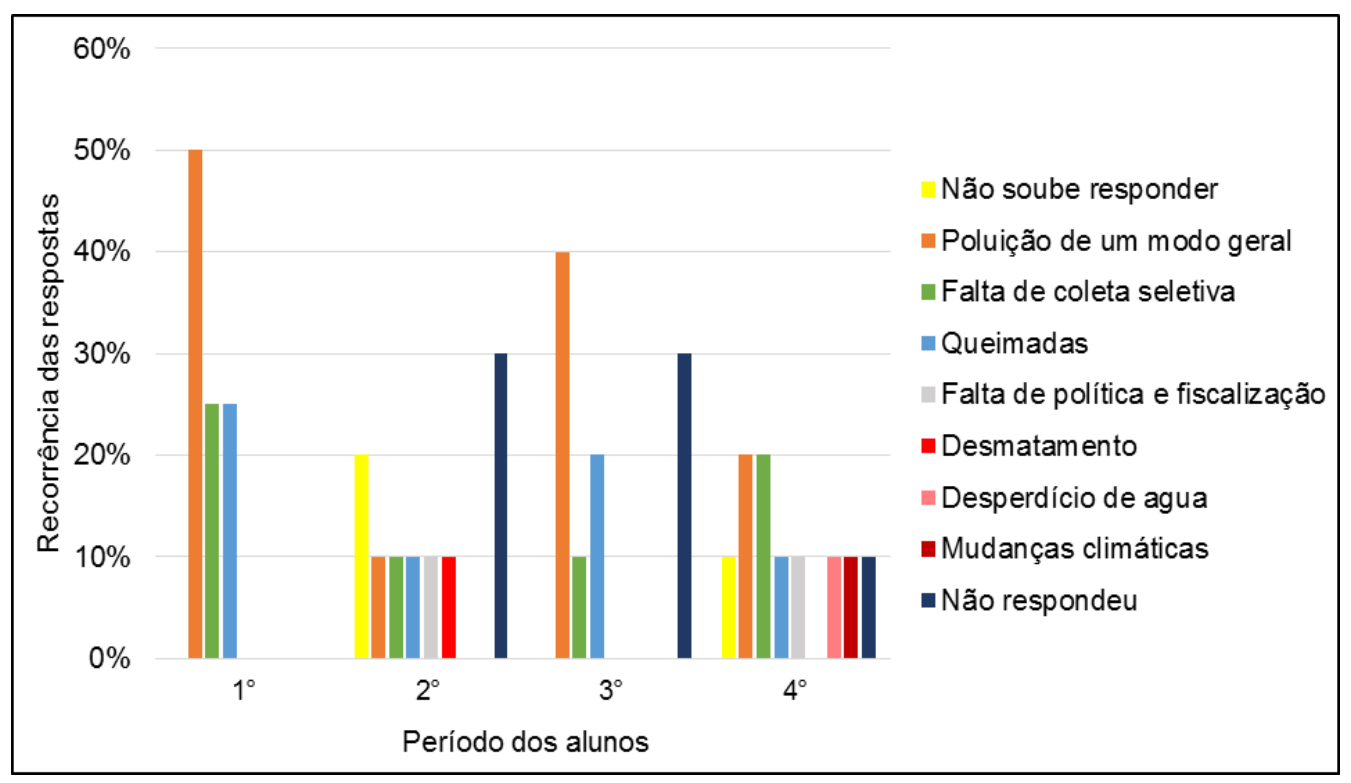

Gráfico 5: Principais incomodos ambientais

A maior parte dos alunos, $27 \%$ respondeu que a poluição de um modo geral é o que mais causa incomodo ambiental no dia a dia, sendo sua maior representatividade 
nos alunos do $3^{\circ}$ período do curso. $\mathrm{O}$ segundo maior incomodo ficou com falta de coleta seletiva e as queimadas na cidade de Manaus, representando $15 \%$ cada uma. Os demais incômodos relatados foram falta de política e fiscalização ambiental, desmatamento, desperdício de água e mudanças climáticas.

Tais aspectos, sinalizam a compreensão da cidade como espaço integrante do ambiente, a qual deve ser tratada e pensada como um organismo vivo, que se regula a partir do bom funcionamento de suas partes, interligadas em um dinâmico processo. $\mathrm{O}$ reconhecimento de seus problemas urge soluções, que muitas vezes transcende a atuação dos indivíduos e exige a mobilização das instituições públicas e seus representantes. Nesse sentido, pode-se oportunizar
a compreensão da percepção da sociedade sobre os problemas e sobre as ações governamentais no processo de gestão pode aproximar o gestor do que a população entende por sua realidade local, ou ainda indicar lacunas existentes no modelo de gestão ambiental (RODRIGUES et al, 2012, p.99)

O aparecimento de cenários distintos exige uma maior atenção ao espaço da cidade no sentido de auxiliar na construção de práticas ambientais em que a participação funcione como referência para a potencialização do desenvolvimento das atividades, bem como dos serviços propostos. Dessa maneira, ainda, oportuniza um desenvolvimento socioambiental, atento ao contexto ambiental e vinculado ao pertencimento local, ressaltando a importância dos valores culturais e históricos da região, bem como dos seus espaços públicos.

Nesse sentido, questionou-se sobre o desenvolvimento de práticas de atividades de EA no dia a dia, $79 \%$ dos alunos disseram que sim, realizam alguma atividade envolvendo a mesma, e sete alunos disseram que não como observado no Gráfico 6. 


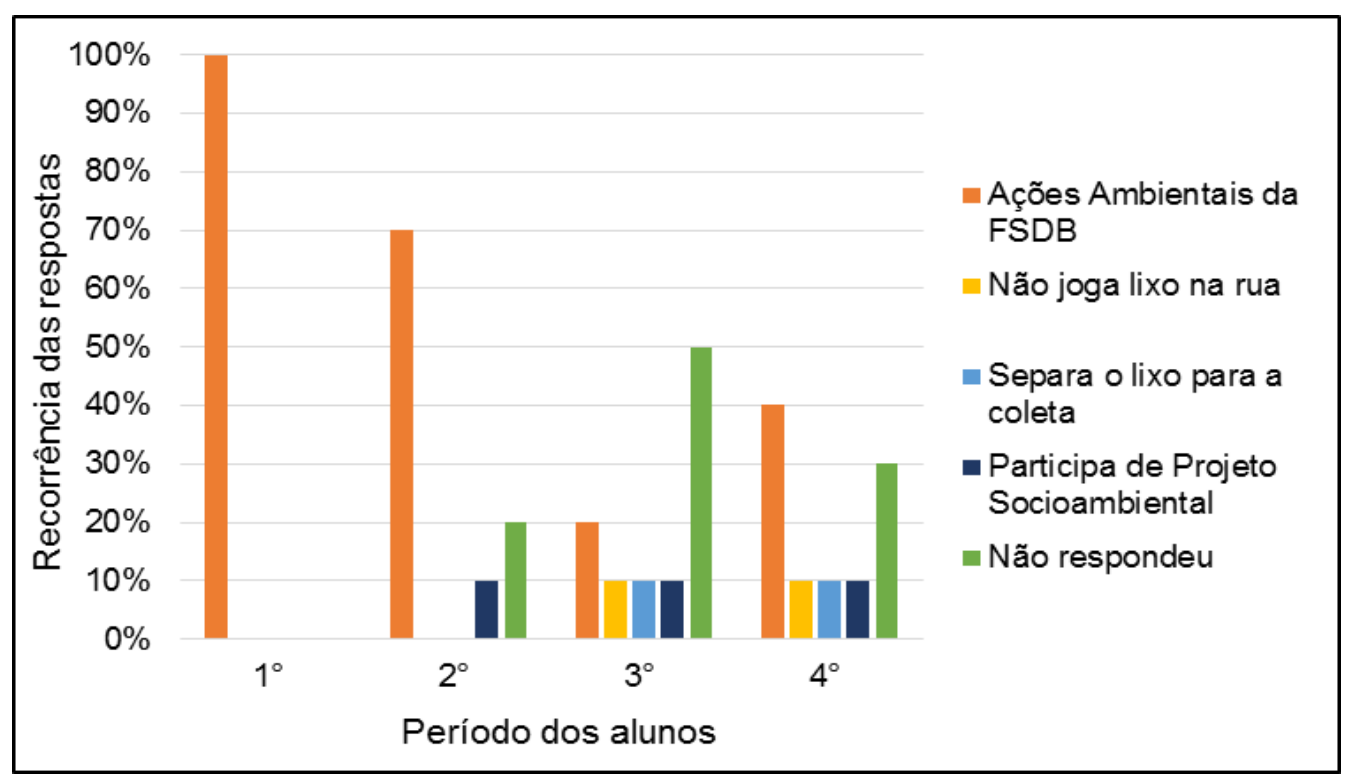

Gráfico 6: Atividades de Educação Ambiental

Dos total de alunos, $50 \%$ disse ter participado de alguma ação ambiental relaizada pela FSDB, o que representa a relevância da universidade formação da consciência crítica dos alunos no que diz respeito aos problemas ambientais. Três alunos afirmaram participar de Projeto Socioambiental e o restante realiza atividades de separação de lixo para a coleta seletiva e o restante não joga lixo na rua e em locais inapropriados.

Nesse quesito, ressalta-se a importâncias das tratativas das temáticas ambientais abordados nas universidades. Historicamente, as universidades são convocadas a apontar os meandros da relação entre o ser humano e o ambiente.

A crise ambiental, atrelada à crise do conhecimento científico, exige um novo papel das universidades. Essas são hoje convocadas a assumirem um posicionamento reflexivo e crítico, a fim de se construir uma nova racionalidade que induza à transformação dos paradigmas científicos tradicionais, promova novos tipos de conhecimentos e integre diferentes saberes, com a participação da sociedade (GUIMARÃES; INFORSATO, 2011, p. 55-56).

O reconhecimento da complexidade das questões ambientais supõe não somente uma recolação epistemológica, mas a mobilização de práticas de ensino, de aprendizagem e de pesquisas e atividades extensivas que compreendam a mobilização de conhecimentos e posturas que visualizem as problemáticas urgentes do mundo contemporâneo, como os problemas ambientais. 
Daí a importância de cursos que se apropriem dessa particularidade, assim, os entrevistados foram perguntados sobre a importância do curso de Gestão Ambiental na FSDB na concepção de EA, e cerca de $82 \%$ deu resposta afirmativa, dois alunos disseram que não, e quatro não responderam a essa questão, como observado no Gráfico 7.

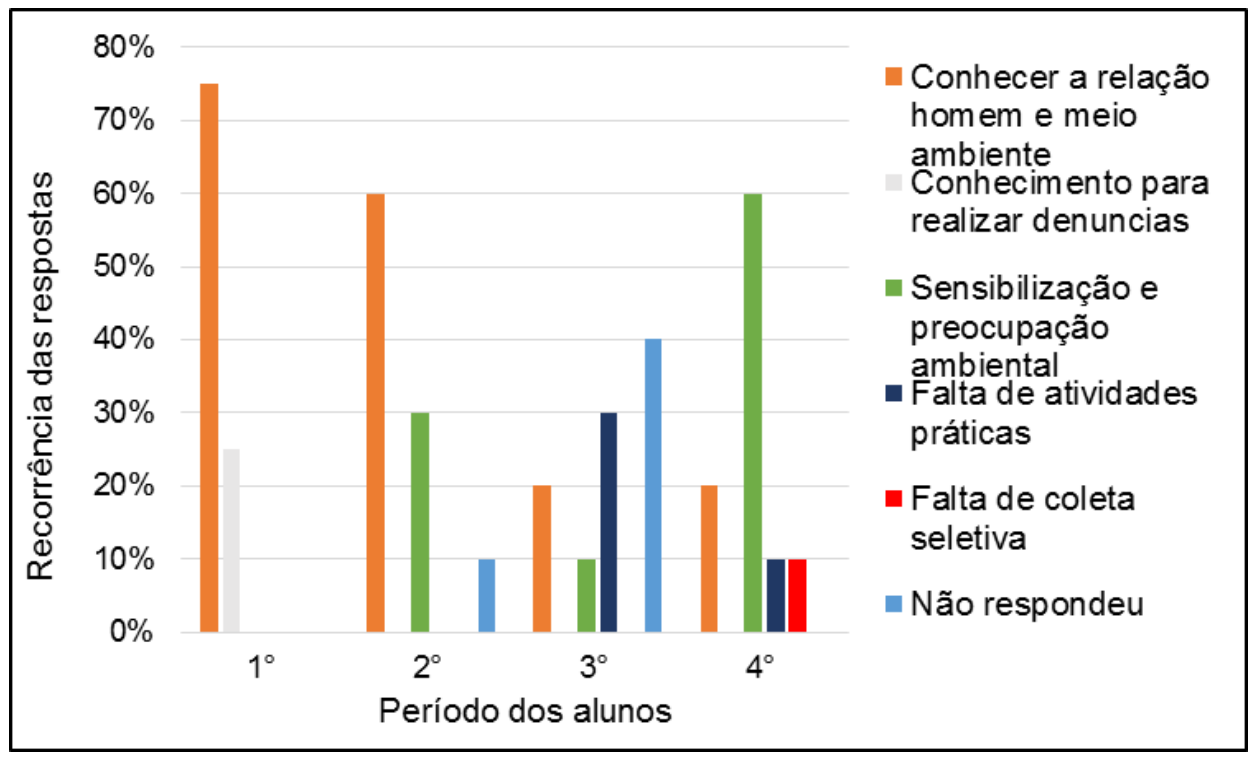

Gráfico 7: Concepção a respeito da Educação Ambiental

Segundo 38\% dos alunos, a FSDB colaborou no sentido de conhecer a relação do homem com o meio ambiente. Outros 29\% afirmaram que a FSDB colaborou no sentido da sensibilização e preocupação ambiental. Um aluno disse que a FSDB colaborou no sentido de ter conhecimento para realizar denúncias. O restante respondeu que apesar da colaboração do curso e da FSDB, ainda há falta de atividades práticas e coleta seletiva na instituição. Quando questinados sobre a frequência que as questões ambientais são abordadas na Faculdade, $72 \%$ respondeu que há grande debate sobre os temas e $28 \%$ disse que raramente tais temas são debatidos ou abordados.

Nota-se a necessidade problematizar as questões ambientais no período de formação universitário como peça de fundamental importância às rápidas transformações sociais que tocam os problemas ambientais. Sendo assim, o espaço de discussão da faculdade pode ser um campo vasto para a exploração de novas 
experiências. Desta perspectiva, emerge a importância de uma formação acadêmica abrangente e profunda que colabore nas problemáticas ambientais.

Nessa perspectiva, a compreensão das problemáticas ambientais é imprescindível para perceber os efeitos das condições do ambiente sobre os comportamentos individuais. Assim, de acordo com esta conjuntura quanto mais identificação houver entre o indivíduo e seu entorno, maior a possibilidade de um comportamento de preservação ambiental, desse modo preservar o ambiente o sujeito estará mantendo sua própria identidade (FREIRE; ALENCAR, 2007).

Daí a pergunta sobre a responsabilização para com os danos ambientais. Do total, $68 \%$ considera a sociedade em geral como o maior responsável pelos danos ao meio ambiente, sendo sua representatividade de resposta maior nos $2^{\circ}$ e $3^{\circ}$ período do curso; $21 \%$ considerou as indústrias e $11 \%$ considera o governo como o maior responsável, como pode ser observado no Gráfico 8.

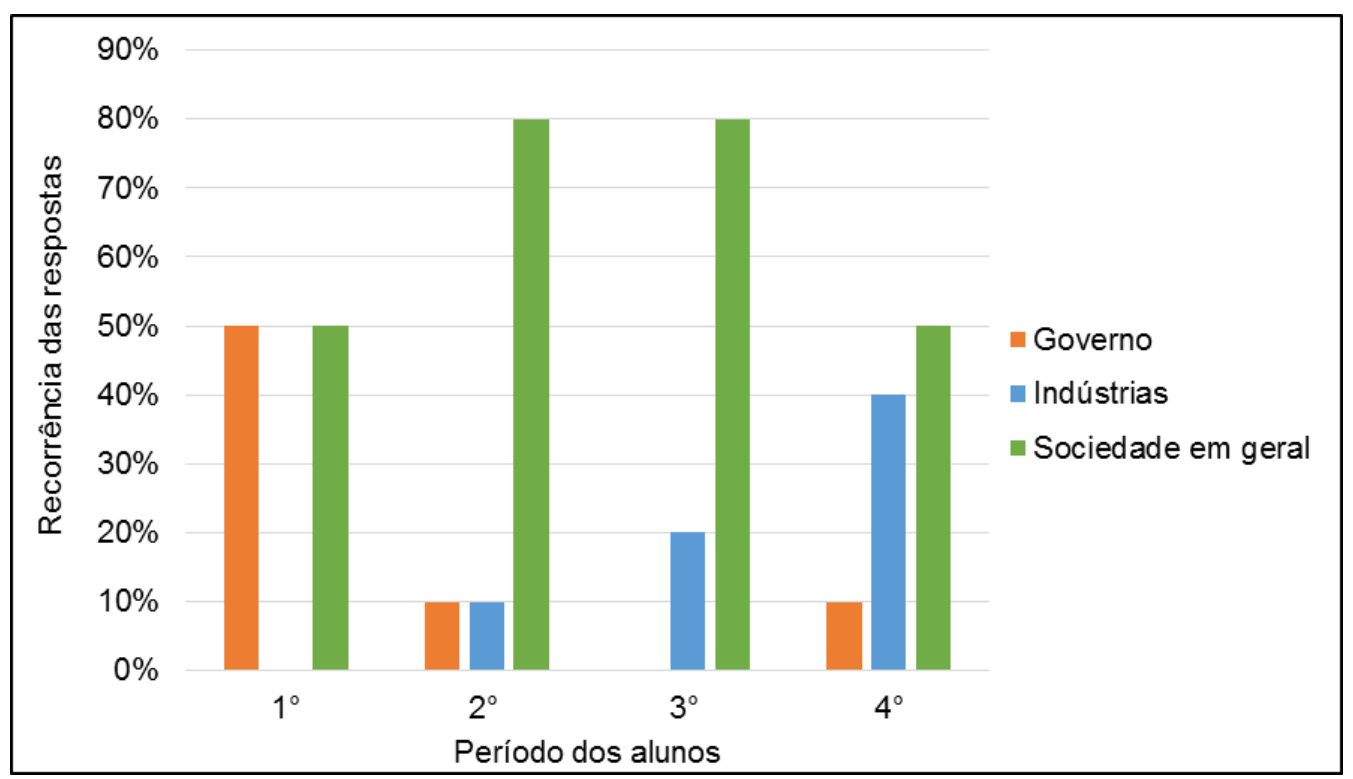

Gráfico 8: Principais responsáveis dos danos ambientais

Nesse sentido, foi solicitado sugestões de melhoria ao meio ambiente, podendo as mesmas serem de nível micro (faculdade) ou macro (cidade, estado ou país). Entre as sugestões citadas a maioria $42 \%$, citou a educação e sensibilização da sociedade em geral para uma melhoria ambiental. Foram citadas ainda a coleta seletiva do lixo, o conhecimento técinico-científico, o pagamento de multas como forma de 
conscientização do cidadão, utilização de ferramentas como o 4Rs (Reduzir, Reutilizar, Reciclar e Repensar o uso), maior propaganda de cunho ambiental e arborização urbana da cidade de Manaus.

Por fim, os resultados apresentados indicaram que embora o curso de Gestão Ambiental possua média duração, 2 anos, por tratar-se de nível tecnologo, existe uma influencia forte na relação dos alunos com a perceção e educação ambiental. Segundo as respostas, a maioria teve seu primeiro contato com práticas e ações socioambientais devido a faculdade.

\section{CONSIDERAÇÕES}

Nas últimas décadas algumas mobilizações foram desenroladas pela busca de perspectivas que viessem melhorar a relação do ser humano com o meio ambiente. Reuniões e Assembleias, como a Eco 92 e a assinatura do Protocolo de Kioto em 1997, por exemplo, movimentam tanto a esfera pública como a privada a pensar sobre a situação ambiental do planeta. Alicerçado nessa conjuntura, a percepção ambiental ora descrita aponta para um contexto, onde inúmeros elementos criam e recriam formas de conhecimentos e expressões que podem indicar possibilidades de como pensar e desenvolver práticas para com ambiente, mas, fundamentalmente, de reconhecer a integralidade na relação ser humano e meio.

Dessa maneira, torna-se inevitável o reconhecimento da percepção ambiental como processo, isto é, como um caminho dinâmico e aberto para pensar e reconhecer modos de vislumbrar a relação ser humano e meio ambiente. Nesse sentido, abre-se para possibilidade de compreender modos e maneiras diferentes de produzir práticas socioambientais viáveis, levando em consideração a realidade polifônica e, marcadamente, diversa que compõe o cenário contemporâneo caracterizado como líquido (BAUMAN, 2001), mas que ao mesmo tempo almeja uma visão holística do conhecimento (CAPRA; LUISI, 2014).

Assim, alicerçado nessa perspectiva, pensar e construir reflexões mediante a percepção ambiental deve-se levar em consideração o cenário contemporâneo, que aponta para um contexto atravessado por múltiplos cenários, por uma pluralidade de aspectos que se entrelaçam, numa teia complexa que circulam influências, interesses e ideologias. Para tanto, por fim, a relação existente entre ser humano e meio ambiente 
pode ser entendida quando se assume em nossas ações parâmetros que buscam uma compreensão recíproca do ser humano com o ambiente, seja ele natural ou construído. Reconhece-se o caráter complementar desses aspectos, ser humano e meio ambiente, na totalidade que é a vida.

\section{REFERÊNCIAS}

ALENCAR, Helenira Fônseca de; FREIRE, J. C. O lugar da alteridade na Psicologia Ambiental. In.: Revista Mal-Estar e Subjetividade - Fortaleza. Vol, VII - N. 2 - p. 305-328 set., 2007.

BRANDÃO, Carlos Rodrigues. Participar-pesquisa. In.: BRANDÃO, Carlos Rodrigues (org.). Repensando a pesquisa participante. São Paulo: Brasiliense, 1984.

BOURDIEU, Pierre. Razões Práticas: sobre a teoria da ação. Campinas: Papirus, 1996.

AMORIM FILHO, O. B. Os estudos da percepção ambiental como a última fronteira da gestão ambiental. São Paulo, 2007. Disponível em: < http://ivair.sites.uol.com.br/marx.htm > Acesso em agosto de 2015.

BAUMAN, Z. Modernidade Líquida. Rio de Janeiro: Zahar, 2001.

CABRAL et al. A Influência da Internet na Educação e no Consumo dos Jovens da Rede Particular e Rede Pública de Ensino. In.: Intercom - Sociedade Brasileira de Estudos Interdisciplinares da Comunicação - XXXII Congresso Brasileiro de Ciências da Comunicação - Curitiba, PR - 4 a 7 de setembro de 2009

CAPRA, F.; LUISI, P. L. A Visão Sistêmica da Vida: uma concepção unificada e suas implicações filosóficas, políticas, sociais e econômicas. São Paulo: CULTRIX, 2014.

CASTOLDI, Rafael; BERNARDI, Rosangela; POLINARSKI, Celso Aparecido. Percepção dos problemas ambientais por alunos do Ensino Médio. Revista Brasileira de Ciência, Tecnologia e Sociedade, v.1, n.1, p.56-80, 2009.

DIAS, G. F. Educação ambiental: princípios e práticas. São Paulo: Gaia, 2004.

FAGIONATTO, S. O que tem a ver a percepção ambiental com a educação ambiental? São Paulo, 2007. Disponível em: <http://educar.sc.usp.ber> Acesso em julho de 2015.

GUIMARÃES, Simone Sendin Moreira; INFORSATO, Edson do Carmo. A universidade e as questões ambientais: a formação de professores em destaque. In.: Bioikos, Campinas, 25(1):53-63, jan./jun., 2011.

MARQUES, L. M. CARNIELLO M. A. GUARIM NETO, G. A percepção ambiental como papel fundamental na realização de pesquisa em educação ambiental. Projeto Saber. Revista Travessias. Vol. 4, $\mathrm{N}^{\circ} \quad 3,2010 . \quad$ Disponível em: http://erevista.unioeste.br/index.php/travessias/article/view/4616 Acesso em novembro de 2015.

OLIVEIRA, L de. O lixo urbano: um problema da percepção Ambiental. In: SIMPÓSIO ANUAL DA ACIESP, 7, 1983, São Paulo-SP: Anais. São Paulo-SP: s. ed., v. 40 (2). P. 48-56, 1983.

OLIVEIRA, L. de. Contribuições dos estudos Cognitivos à Percepção Geográfica. Revista de geografia. USP. V. 3, p. 61-72, 1997. 
RICHARDSON, Roberto Jarry. Pesquisa social: métodos e técnicas. 3. ed. São Paulo: Atlas, 1999.

RODRIGUES ET AL, Mariana Lima. A Percepção Ambiental Como Instrumento de Apoio na Gestão e na Formulação de Políticas Públicas Ambientais. In.: Saúde Soc. São Paulo, v.21, supl.3, p.96-110, 2012.

RUCHEINSKY, A. Meio ambiente e percepção do real: os rumos da educação ambiental nas veias das ciências sociais. Revista Eletrônica do Mestrado em Educação Ambiental. P. 2644, out-dez. 2001.

SANTOS, MILTON. Por uma outra globalização: do pensamento único ao pensamento universal. 11.ed. Editora Record: São Paulo, 2004.

TRIVIÑOS, A. N. S. Introdução à pesquisa em ciências sociais: a pesquisa qualitativa em educação. São Paulo: Atlas, 1987. 